\title{
Der Obelos im masoretischen Texte.
}

Von Samuel Krauss in Budapest.

Die Anwendung des Obelos als textkritisches Zeichen in der Bibel war bisher nur aus dem Bibelwerke des Origenes bekannt; im masoretischen Texte kannte man ein solches Zeichen nicht. Man fand das stillschweigend sehr natürlich; der Obelos, ein von den Homer-Abschreibern längst angewandtes Zeichen, konnte nur von Origenes, diesem von griechischem Geiste beseelten Gelehrten, auch für die Herstellung des Bibeltextes in Anwendung gebracht werden; in rabbinischen Kreisen mochte man sich dieses Zeichens nicht bedienen.

Dem ist aber nicht so. Ein allen Bibellesern zur Genüge bekanntes Zeichen, der umgekehrte Buchstabe Nun (נ' הפוכה) in Numeri 1o vor Vers 35 und nach Vers 36 des masoretischen Textes, scheint nichts anderes als ein jüdischer Obelos zu sein.

Von diesem Zeichen "heisst es in dem deuterokanonischen talmudischen Traktat Sopherim (Schreiber) c. 6 Artikel I wie folgt: הכותב 'צריך לעשות שיעור בפתיחה של ויהי בנסע המפרים מלמעלה ומלמטה שהוא ספר בפני עצמו וי"א שמקומו בנסיעת דגלים In diesem Satze müssen wir zunächst eine von dem Kritiker R. Elia Wilna stammende Correctur anbringen; der Ausdruck פתיחה (Anfang, Beginn) nämlich ist unpassend, weil das fragliche Zeichen am Ende, des Stückes nicht minder 
zu stehen hat als an dessen Anfang, und so muss dafür der Ausdruck פרשה (Section, Abschnitt) gesetzt werden. Der Satz lautet nun in der Uebersetzung: Der [Thora-]Schreiber muss ein Spatium machen in der Section von 'הi' etc. (Num. 10, 35) oben und unten, weil dies ein Buch für sich ist; Andere jedoch sagen, dass sein Ort [der Ort des Abschnittes] in dem Abschnitte des Fahnenzuges (Num. IO, I I-28) wäre. Das heisst doch wohl, jenes Spatium hake nach Einigen den Grund, darauf hinzuweissen, dass Num. 10, 35. 36 ein besonderes Buch bilde; nach Anderen weist es darauf hin, dass die angegebenen zwei Verse eigentlich in dem Abschnitt über den Fahnenzug am Platze wären; deutlicher gesagt: die zwei Verse sind am unrechten Platze, besser ständen sie nach Vers 28, denn die Geschichte mit Chobab (29-32) unterbricht den Zusammenhang.

All dies soll durch ein Spatium angedeutet sein. Man muss gestehen, dass ein Spatium zum Zwecke solchen Hinweises nicht gut geeignet ist, denn im Pentateuch befinden sich Hunderte von Spatien ohne solchen Charakter; auch hätte man statt להניח שיעור etwartet. Demnach ist der Ausdruck שיעור wenigstens verdächtig. $R$. Elia Wilna liest in der That סימן dafür: onjeiov Zeichen, gewiss auf Grund einer Barajtha im babylonischen Traktat Sabbath I I5b (unten), wo der Satz wie folgt lautet: פרשה

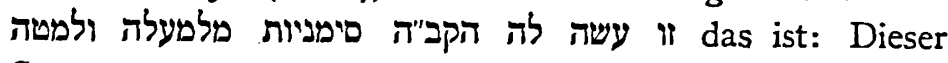
Section sind oben und unten von Gott Zeichen beigefügt. Also sind, um erst den Text sicherzustellen, die von uns gewählten Ausdrücke פרשה טימן als authentisch erwiesen. Damit könnten wir uns auch schon begnügen, denn der Satz hat nun einen guten Sinn: Zeichen oben und Zeichen unten; wie das Zeichen beschaffen sei, wird entweder als bekannt vorausgesetzt, oder es wird der Wahl des Copisten überlassen. 
Genauer erwogen, kann nur die freie Wahl des Copisten in Betracht kommen, denn der Schreiber, der die allererste Thorarolle copirte und der zu allererst die fragliche Section mit einem Zeichen versehen wollte, konnte hinsichtlich der Beschaffenheit des zu wählenden Zeichens nur mit sich selbst zu Rathe gehen. Er machte irgend ein Zeichen (סימן), das zunächst gar keinen Namen hatte. So, סימניות pur et simple, lautet der Satz auch in dem midraschischen Sammelwerke zu Num. $\$ 729$. Eine Mischna, Sabb. I2, 3, nennt eine gewisse Art von Schriftzeichen ebenfalls nur טימניות (daneben auch die Leseart סממניות, s. Krauss-Löw, Lehnwörter II, 387). Im jerusalemischen Talmud (Sabb. I3 C Zeile 56) wird als Autor dieses Theiles der Mischna R. Jose genannt, derjenige R. Jose, der in der Mischna jene unvollständige Schrift einfach nur "Spur" (רושם) nennt. Demnach sind סימן und in diesem Betracht einander gleich. Der Thora-Schreiber wollte also mit jenem Zeichen keine bestimmte Figur, sondern nur die Spur dessen geben; dass es mit jenen zwei Versen in Numeri eine eigene Bewandtniss habe. Auf diese Weise ist die Form des Zeichens natürlich ganz nebensächlich, und darum begnügen sich die angeführten Quellen, welche die ältesten zu sein scheinen, mit der allgemeinen Bezeichnung "Zeichen" (סימן).

Ebenso ist סימניות der Ausdruck in derjenigen Barajtha (Rosch ha-Schanah 17 b), in welcher von demselben nicht minder bekannten Zeichen (in Ps. 107, 23-3I) die Rede ist (s. Blau, Masoretische Untersuchungen, Strassburg i. E. I893; S. 41).

Nur durch den tannaitischen Midrasch Sifre (Numeri z. St.) erfahren wir; dass das fragliche Zeichen aus einem Punkte (נקור) besteht; dieser Punkt hat sich in einigen Codices sogar noch erhalten (Blau a. a. O. 43). Diese Angabe scheint mir zu den früher besprochenen Angaben durchaus 
nicht im Gegensatze zu stehen, denn ein einfacheres Zeichen als ein Punkt lässt sich nicht gut denken. Will man aber einen Unterschied dennoch statuiren, so wird wohl zugegeben werden müssen, dass die Angaben, in welchen bloss von Zeichen im Allgemeinen die Rede ist, älter und ursprünglicher sind, wogegen die Bezeichnung als Punkt schon eine Entwickelung darstellt.

Wie ist nun daraus נון הפוכה (umgekehrtes Nun) oder נון מנוזרת (vereinzeltes Nun) geworden, wie in der Masora dieses Zeichen genannt wird? Geistreich sagt darauf Blau (a. a. O.), dass man statt des Punktes, welcher nicht gut sichtbar war, ein 'y (Abbreviation von נקוד) schrieb, damit man jedoch dieses Nun nicht für zum Texte gehörig halte, schrieb man es in umgekehrter Form. Nun drängt sich aber die Frage auf, warum man sich in anderen Fällen mit der Setzung eines blossen Punktes begnügte? Solcher Fälle gibts ja viele! Warum sorgte man nicht dort für auffallendere Zeichen? Wenn man sich ferner scheute, zum Thoratexte etwas hinzuzuschreiben, warum duldete man das Nun, auch wenn dieses ein bloss umgekehrtes ist?

Ich denke mir darum den Vorgang anders. Die Thora-Copisten ahmten die griechischen Copisten nach, die als eines ihrer kritischen Zeichen den Spiess

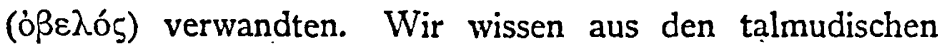
Schriften, dass die Juden die Form der griechischen Buchstaben sehr gut kannten, so z. B. ist schon in der Mischna von dem Buchstaben $\chi^{i}$ (כי יוונית) die Rede, und auch andere orthographische Eigenthümlichkeiten der griechischen Schrift, z. B. tachygraphische Noten, waren den Juden wohl bekannt (s. meine Abhandlung in Byz. Zeitschr. II, 5 I7). Jener Spiess nun hatte, wie man wenigstens gewöhnlich annimmt, die Figur $\sim$, also eines liegenden $S$, und ungefähr 
dieselbe Form zeigt auch das umgekehrte Nun, besonders wenn man den einen Haken, wie oft zu sehen, umdreht: J, liegend also $\longrightarrow$ (nicht $\neg$ ).

Um die Beschaffenheit dieses Zeichens in unserer Bibelausgabe festzustellen, habe ich einige wichtigere Drucke eingesehen. Rabbinische Bibel Bragadin Venedig 16I7 hat vorher und nachher gar kein Zeichen, doch $y \circ[]$ und כמתהאינים, ebenso Amsterdam I724. Dies scheint mir ganz verfehlt und gegen die ursprüngliche Meinung zu sein, vgl. oben den Wortlaut: סימניות מלמעלה ולמטה. In der kleinen Ausgabe Amsterd. 1705 van der Hooght ${ }^{x}$ steht vorher und nachher [, am Margo נון הפוכה, während במתאנגים und ganz regelmässig gedruckt sind; ebenso Amsterd. ohne Vokale I70I; ebenso Leyden I6I0, doch ist hier das Zeichen [ den

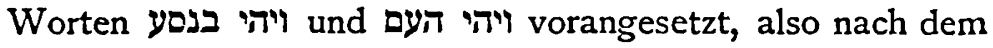
Zeichen $D$ und D סתומה = פתוחה D geschlossene und offene Section), was wiederum fehlerhaft ist, denn nach $\square$ gesetzt bezieht sich das Zeichen nicht mehr auf 10, 35. 36, sondern auf II, I. In der ungemein verbreiteten Ausgabe von M. Letteris (Berlin, Bibelgesellschaft), die sich des Rufes der Correctheit erfreut, finde ich den ähnlichen Fehler, dass [, übrigens fett gedruckt, vorher vor $\square$ gesetzt ist, während es richtiger nach 0 stehen sollte. Dagegen richtig in מקראות גדולות Warschau 1869 vorher und nachher innerhalb von $D$ und $D$, so dass es sich richtig auf die fraglichen zwei Verse bezieht. Ausserhalb dieser Zeichen steht das umgekehrte Nun schon-in dem Holzdruck Anvers (אנוירשה)

I Biblia hebr. sec. ed. J. Athiae a J. Leusden rec. E. v. d. Hooght (in Biblioth. theol. et philos. Lugd. Bat. 1900 trägt sie die Nummer 1343); ihr Vorbild ist Amst. 1701, herausgeg. v. David Nunez Torres, gedruckt bei Athias (hebr. פטיאש geschrieben, was viell. Etias zu transcribieren). Ich nenne noch Bibl. Hebr. Utrecht I joI (ib. no 1342), wo das umgekehrte Nun vor $D$ und $\triangle$ steht; ferner Biblia hebr. ed. Menasse b. Israel. Amstermad 1635, wo so[ב und כמתאים gedruckt ist. 
1566. In der Bibl. Hebr. von Hahn, Lips. 1838 und wohl auch in anderen christlichen Drucken findet sich überhaupt kein Zeichen.

Der Obelos wurde, wie schon bemerkt, schon von den Homeros-Copisten angewandt; er fand unter Anderem Verwendung, wenn angegeben werden sollte, dass das betreffende Stück nicht am rechten Platze sei. Dass der Obelos auch im Mittelalter und sogar in Documenten verwendet wurde, lehrt die Culturgeschichte (s. W. Wattenbach, Das Schriftwesen im Mittelalter, Leipz. 1871, S. 149 und 193). Kein Wunder, dass dieses Zeichen auch in der BibelDiaskeue Verwendung fand. Die Reste von Origenes' Hexapla herausgebend, handelt Field auch von diesem Zeichen ausführlich (p. LII ff.). Er citirt unter Anderem

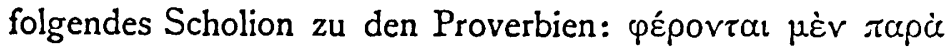

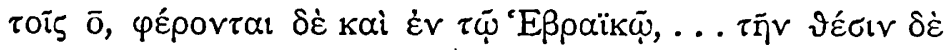

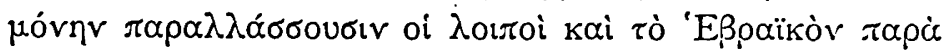

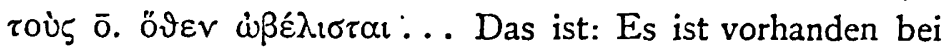
der Septuaginta, es ist vorhanden im Hebräischen, nur in Bezug auf die Setzung weichen die Uebrigen und das Hebräische von der Septuaginta $a b$, und darum wird es mit Obelos versehen. Für den Unterschied in der Setzung ist also der Obelos das Zeichen. Field belegt das auch mit anderen Beispielen. Auch weist er das oben beschriebene Zeichen $\sim$ vielfach aus; ich füge hinzu, dass in dem hexaplarischen syrischen Texte ed. Middeldorp der Obelos immer dieses Zeichen hat. Wenn nun das in dem masoretischen Texte befindliche Zeichen נון הפובה dem griechischen Obelos entspricht, so verstehen wir auch die Motivirung: לומר שאין וה מקומה ,das besagt, dass die zwei Verse nicht hier am Platze sind", und dieangeführte Stelle in Sopherim gibt sogar den richtigeren Platz in positiver Weise an.

Diese Stelle in Sopherim 6, I zeigt eine wichtige Variante 
auf: anstatt des ohnedies verdächtigen שיעור haben manche Ausgaben שיפור שיפור (šippud oder šippur). Nach dem Vorgange Neubauer's, dessen hiehergehörige Aeusserung mir nicht näher bekannt ist, wird diese Leseart von Blau zu wiederholten Malen (Mas. Unters. S. 99; Magyar-ZsidóSzemle I7, I 53 und Hebr. Bibliogr., neue Folge 4, 30) für unverständlich erklärt und verworfen, wobei er zweimal שפור mit $r$ und einmal שפוד mit $d$ drucken lässt. Die Leseart darf nicht verworfen werden, denn die schwierige Leseart ist bekanntermassen immer authentischer als die leichtere. Auch sagt Blau, das Neubauer eine neue Leseart, שיעור, citire, wo doch das die vulgäre Leseart, der textus receptus ist; so haben z. B. die Talmud-Ausgaben Prag 1833 und die grosse Wilnaer Ausgabe nur diese Leseart! Ich halte nun שיפוד fur die allein richtige Leseart, aus der erst durch Copistenschuld die sinnlose Leseart שיעור geworden ist; שיפור, welches ebenfalls sinnlos ist, kommt nicht in Betracht. Dagegen hat einen guten Sinn; von שפור veru, Spiess, das ich (Lehnwörter.s. v.) für

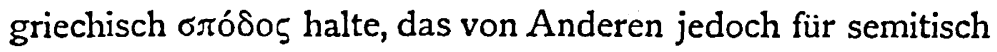
erklärt wird, kommt auch das Verb שפד vor, und daraus . ist als nomen actionis שיפוד in derselben Weise gebildet, wie das in der Masora häufige ניקוד van van wass, dass

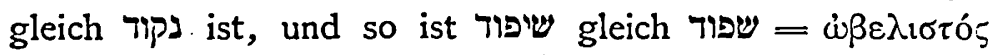
mit Obelos versehen. Die Stelle in Sopherim besagt also: Der Thora-Schreiber muss in der Section Num. 10, 35. 36 vorher und nachher eine Obelisirung (sit venia verbo!) machen, weil sie ein Buch für sich ist; Einige sagen, dass ihr Platz in dem Abschnitt vom Fahnenzug wäre. Während nun die Barajtha, hier wohl die älteste Quelle, bloss von einem Zeichen im Allgemeinen spricht, nennt Sifre dasselbe Zeichen schon einen Punkt - doch bemerke ich, dass נקוד auch den allgemeinen Sinn von „Bezeichnung“ verträgt - 
und in dem noch später, etwa im 7. Jahrhundert abgefassten Sopherim, dessen Bestandtheile jedoch gleichwohl auf ganz frühe Zeiten zurückgehen können, wird dasselbe Zeichen in ganz eigentlicher Weise Obelisirung genannt. Ich glaube nicht, dass die Figur des Zeichens je eine andere als die des Obelos gewesen wäre; schon der allererste Schreiber, der die beiden Verse aus Versehen an den unrechten Ort gesetzt hatte, wird zur Richtigstellung des Fehlers den griechischen Obelos angewandt haben.

Alle isagogischen Lehrbücher führen jene talmudische Motivirung des umgekehrten Nun, wonach aus zwei Versen ein ganzes Buch creirt werden soll, getreulich an, während sie die gesunde kritische Bemerkung, dass die zwei Verse versetzt worden seien, zumeist verschweigen; das sollte, glaube ich, anders sein. Die Septuaginta haben die beiden Verse in der That vor Vers 34. Auch in Psalm 107 erhält man einen besseren Sinn, wenn man die Weisung des umgekehrten Nun befolgend, jene Verse in sinniger Weise umstellt. Dies hat Ginsburg gut erwiesen (Christian D. Ginsburg, Introduction to the Massor. Critical Edition of the Hebrew Bible, London 1897, p. 34I ff.). Ich stimme auch mit Ginsburg in Bezug auf die Bedeutung des umgekehrten Nun völlig überein: They are simply intended to take the place of our modern brackets to mark that the passages thus bracketed are transposed.

Einer nachträglichen Bemerkung von Blau (in M. Zs. Szemle 17, 258) verdanke ich die erfreuliche Nachricht, dass M. Rahmer in seinem jüd. Litteraturblatte 1900 Nr. 6 שיפוד שn in Sopherim gleichfalls für Obelos erklärt. Eine mündliche Unterredung mit Dr. M. Rahmer in Magdeburg bestärkte mich seitdem ebenfalls von der Richtigkeit dieser Erklärung. 